\title{
Factors affecting the daily feed intake and feed conversion ratio of pigs in grow- finishing units: the case of a company
}

\author{
C. R. Pierozan ${ }^{1}$, P. S. Agostini², J. Gasa², A. K. Novais ${ }^{2}$, C. P. Dias', R. S. K. Santos ${ }^{1}$, M. Pereira Jr ${ }^{1}$, J. G. Nagi ${ }^{1}$,
} J. B. Alves ${ }^{1}$ and C. A. Silva ${ }^{1}$

\begin{abstract}
Background: The aim of this study was to use mathematical modeling to identify and quantify the main factors that affect daily feed intake (DFI) and feed conversion ratio (FCR) in grow-finishing (GF) pig units. We evaluated the production records of 93 GF farms between 2010 and 2013, linked to a company, working in a cooperative system, located in western Paraná State, Brazil. A total of 683 batches, consisting of approximately 495,000 animals, were used. Forty production factors related to the management, health, plant and equipment, nutrition, genetics and environment were considered. The number of pigs per pen, type of feeder, origin and sex (the last two variables were combined in the models) of the animals and initial and final body weights were included in the final models to predict DFI and FCR (dependent variables). Additionally, the duration of the GF phase was included for the parameter FCR. All factors included in the final models had significant effects for both dependent variables.
\end{abstract}

Results: There was a reduction in DFI $(0.04 \mathrm{~kg})(P<0.001)$ and an improvement in FCR $(6.0$ points $)(P<0.001)$ in batches from pens with less than 20 animals compared with batches from pens with more than 20 animals. In barns with "other" feeder types (mostly the linear dump type) different of conical semiautomatic feeder, a reduction of DFI $(0.03 \mathrm{~kg})(P<0.05)$ and improved FCR $(3.0$ points) $(P<0.05)$ were observed. Batches of barrows from units specialized for producing piglets (SPU) had higher DFI (approximately $0.02 \mathrm{~kg})(\mathrm{P}<0.01$ ) than batches of females and batches of mixed animals from SPU, and batches of mixed animals from farms not specialized for piglet production (farrow-to-finish farms). Batches of females from SPU and mixed batches from SPU had better FCR (5.0 and 3.0 points respectively) $(P<0.001$ and $P<0.001$, respectively) than batches of piglets originating from farrow-to-finish farms. The variables selected for the final models explained approximately 50 and $64 \%$ of the total variance in DFI and FCR, respectively.

Conclusions: The models are tools for the interpretation of the factors related to the evaluated parameters, aiding in the identification of critical aspects of production. The main parameters affecting DFI and FCR in this company during the GF period were the number of pigs per pen, the type of feeder used and the combination origin-sex of the animals.

Keywords: Feed intake, Feed conversion ratio, Grow-finishing pigs, Production factors

\footnotetext{
*Correspondence: pieroagostini@hotmail.com

${ }^{2}$ Grup de Nutrició, Maneig i Benestar Animal, Department de Ciència Animal

i dels Aliments, Universitat Autònoma de Barcelona, 08193 Bellaterra, Spain

Full list of author information is available at the end of the article
} 


\section{Background}

Feed accounts by approximately $65-75 \%$ of pig production cost and $75 \%$ of that feed consumed in the growfinishing (GF) phase [1]. Despite the economic importance of the GF phase, few studies of Brazilian farms have aimed to quantify the effect of the main production factors over the performance of GF pigs. Although the major factors affecting pig performance are known [2-4], such as genetics, nutrition and feeding, housing conditions and health, studies relating these variables with each other, especially genetics to nutrition and feeding $[5,6]$ and health [7] are scarce. Those that relate production parameters to the conditions of facilities and equipment involved [8] are even scarcer. Agostini et al. [9] have established a relationship among production factors and performance indexes from more than one million pigs in GF phase from eight different companies in Spain. From the results important recommendations were made, both for immediate changes in feeding, nutrition and management and for future action in genetics, construction and environmental issues. The same authors [10] also indicated that models within company are more reliable than models obtained among companies, since each company has its specific management, nutrition and facilities features across its farms.

When evaluating the effects of production factors upon a specific livestock parameter, mathematical models are a potentially effective tool. These models are primarily intended to represent a simplification of reality that from a mathematical point of view, describes a phenomenon based on factors of interest [11]. The use of modeling has allowed researchers in agricultural systems to develop concepts, methods and tools to direct the activity as a whole [12]. According to Dent et al. [13], the model construction process itself contributes to a better understanding and description of a given system.

The aim of this study was to use mathematical models to identify and quantify the impact of various intrinsic and extrinsic production factors on the daily feed intake (DFI) and the feed conversion ratio (FCR) in grow-finishing (GF) pig farms of a single company. The results may help company managers to predict the production rates and to focus their limited resources in the areas of higher profit.

\section{Methods}

\section{Data collection}

Animal Care and Use Committee approval was not necessary as this study used a database of a survey carried out in existing commercial farms.

Between 2010 and 2013, the historical production parameters of 683 batches of pigs in GF phase (totaling approximately 495,000 animals) from all the 93 farms (7.34 batches per farm) integrated to a company located in Western Paraná (Brazil) were used.

The workflow followed the study conducted by Agostini et al. [9] and was developed in two stages. In the first stage the variables of interest were chosen, representing the most important factors affecting the livestock production records of the company. Then a model that offers reliability, speed and efficiency in collecting the information was later established. Differently from the study of Agostini et al. [9], the data belong to all farms integrated in the company and with a greater number of batches per farm. All farms provided batches from different seasons.

The dependent and independent variables were selected by taking into account recent scientific work and the field experience of the company's staff. The dependent variables choose were the DFI and FCR. The total feed intake per animal was calculated as the total amount of feed in kilograms delivered to each batch during the GF period, minus the amount of feed remained in the silos when the animals were sent to slaughter, divided by the number of pigs marketed. Then the DFI was calculated as the total feed intake per animal divided by the average number of days that the animals remained in the GF unit. FCR was obtained by dividing the total feed intake of each batch by the difference between the total kilograms of pigs sent to slaughter and the total kilograms of pigs that entered at the GF batch. Mortality rate was not considered in the calculations of DFI and FCR since feed intake and body weight of dead animals were not registered.

Initially, four continuous independent variables were evaluated: number of pigs placed (NPP), initial weight (IW), final weight (FW), and duration of GF phase (DGF) as presented in Table 1. The NPP was the total number of pigs housed in the GF units. The IW corresponded to the pigs' live weight in kilograms when they

Table 1 Descriptive values of dependent and independent continuous variables selected for the final models

\begin{tabular}{lllllllll}
\hline Variable & $N^{\circ}$ batches & Mean & SD & Minimum & $1^{\text {st }}$ quartile & Median & $3^{\text {rd }}$ quartile & Maximum \\
\hline Number of pigs & 683 & 726 & 430 & 200 & 499 & 608 & 919 & 2393 \\
IW (kg) & 683 & 22.7 & 1.2 & 18.9 & 22.2 & 22.8 & 23.4 & 27.6 \\
FW (kg) & 683 & 117 & 5 & 100 & 113 & 117 & 120 & 132 \\
DGF (day) & 683 & 107 & 4 & 96 & 104 & 107 & 110 & 120 \\
DFI (kg/pig) & 682 & 2.15 & 0.10 & 1.82 & 2.09 & 2.15 & 2.22 & 2.48 \\
FCR (kg/kg) & 682 & 2.45 & 0.12 & 2.15 & 2.36 & 2.45 & 2.54 & 2.86 \\
\hline
\end{tabular}

SD standard deviation, $I W$ initial weight, $F W$ final weight; $D G F$ duration of growing-finishing phase, $D F I$ daily feed intake, $F C R$ feed conversion ratio 
entered the GF units, and the FW to the average live weight of pigs at slaughter. The DGF was the period, in days, that animals remained in the GF unit. Because the data concerning the NPP were not normally distributed, this variable was considered as categorical.

Approximately forty categorical independent variables were also evaluated (Table 2) that represented factors of production related to facilities, herd health, and aspects of livestock management systems and nutrition. To obtain this information, questionnaires were given both as digital spreadsheets (Excel 12.0, Office 2007) and on paper.

\section{Statistical analysis}

The collected data were entered into an Excel spreadsheet before statistical analysis was carried out. The analysis was done in two phases: exploratory analysis and model development as previously carried out by Oliveira et al. [8], Agostini et al. [14] and Maes et al. [15]. In the exploratory analysis phase, a frequency study of the categorical variables was conducted using the SAS FREQ procedure (SAS Inst., Inc., Cary, NC, USA, version 9.2) (occurrence percentages in Table 2). Categorical variables with absence of variability among their categories (more than $90 \%$ of the total batches included to a given category) were initially excluded for further statistical analysis (Table 2).

Measures of central tendency (mean and median) and dispersion (standard deviation, quartiles and amplitude) for the continuous variables were computed using the SAS MEANS procedure (Table 1). The distributions of continuous variables were evaluated using the SAS UNIVARIATE procedure. In all these analyses, the batch was considered the experimental unit, defined as a single group of piglets that came from the nursery phase and were housed in a GF unit until slaughter. All batches were managed as all-in all-out systems.

Mixed linear regression models were fit using the SAS MIXED procedure, using the variables that were coded in the first phase as predictors. The effect of farm and batch within the farm were considered as random factors, and the variance was estimated using the restricted maximum likelihood method. The comparison of the final models' goodness of fit was based on the proportion of variance explained by the different models, using the coefficient of determination $\left(R^{2}\right)$ as a parameter.

In the second phase, a single regression model was used where each variable was included as a fixed effect for each single dependent variable. The independent variables with $\mathrm{P} \leq 0.20$ were selected for use in the multivariate analysis.

Pearson and Spearman correlations were performed between independent variables to avoid multicollinearity between continuous variables and confounding problems between categorical variables. When two variables had high correlation coefficients (absolute value $\geq 0.60$ ), only one was used in the multivariate analysis; the choice between them was made by comparing the $P$ values in the univariate analysis, and additionally evaluating their biological relevance with respect to the dependent variable. In that case the variables "origin" and "sex" of the animals showed a relationship being used only in particular combinations and hence both were grouped as a single combined variable (ORIGSEX).

Subsequently, all independent variables selected in the univariate analysis were submitted to the procedure "stepwise", where all factors with $P<0.05$ were kept in the final multivariate model. Fixed-effect testing was based on the F-test with denominator degrees of freedom approximated by the Satterthwaite's procedure. Significant interactions $(P<0.05)$ between the variables in the multivariate model were tested and included.

After obtaining the models for each dependent variable, the residuals were plotted against the predicted values to check the homogeneity of variances and the presence of outliers. All the factors with $P<0.05$ in the final models for each of the two dependent variables (DFI and FCR) were considered statistically significant.

\section{Results \\ Daily feed intake}

The DFI per pig per batch was $2.15 \pm 0.10 \mathrm{~kg}$ (ranging from 1.82 to $2.48 \mathrm{~kg}$ ) (Table 1). Multivariate regression analysis indicated that DFI was influenced by the number of pigs per pen $(P<0.001)$, type of feeder $(P=0.03)$, ORIGSEX $(P=0.01)$, IW $(P<0.001)$ and FW $(P<0.001)$ (Table 3). The total variance of DFI in the model without predictors (the null model) was 0.009541 , where 0.00346 (36.3\%) was observed between farms and 0.006081 (63.7 \%) between batches from the same farm. After the variables were included in the multivariate model, the residual variance for the DFI was reduced to 0.004806, which indicated that approximately $50 \%$ of the total variance of DFI was explained by the variables included in the final model (Table 4). The residual distribution of DFI is highlighted in Fig. 1. The percentages of the variance explained between farms and between batches within a farm, using the final model for DFI, were 60.8 and $43.3 \%$, respectively (Table 4 ).

In batches with less than 20 animals per pen, the DFI per pig was lower $(0.04 \pm 0.01 \mathrm{~kg})$ than in batches with more than 20 animals. In pens where the feeder was not semiautomatic (of these, the most common type was the linear dump one), a reduction of DFI was observed (approximately $0.03 \pm 0.01 \mathrm{~kg}$ ). A higher DFI (approximately $0.02 \pm 0.01 \mathrm{~kg}$ ) was found in batches of barrows from SPU than in batches of females from SPU and batches of animals of mixed sex from both SPU and farrow-to- 
Table 2 Description of independent categorical variables and their percentage of occurrence in the company

\begin{tabular}{|c|c|}
\hline Variable & Percentage of batches in each category \\
\hline Semester of placement ${ }^{\mathrm{b}, \mathrm{e}}$ & $\begin{array}{l}\text { Summer / autumn (48.76 \%); winter / } \\
\text { spring (51.24 \%) }\end{array}$ \\
\hline $\begin{array}{l}\text { Number of animals } \\
\text { placed }^{\text {b, }}\end{array}$ & $\begin{array}{l}<500(20.78 \%) ; 500-1000(55.04 \%) \\
>1000(24.18 \%)\end{array}$ \\
\hline Number of barns $s^{b, f}$ & One (42.14 \%); two or more (57.86 \%) \\
\hline Stall age $\mathrm{b}^{\mathrm{f}}$ & $\begin{array}{l}<5 \text { years }(20.78 \%) ; 5 \text { to } 10 \text { years }(53.26 \%) ; \\
>10 \text { years }(25.96 \%)\end{array}$ \\
\hline Reform of facilities ${ }^{\mathrm{b}, \mathrm{f}}$ & Yes (21.07\%); no (78.93 \%) \\
\hline $\begin{array}{l}\text { Number of pigs per } \\
\text { pen } b, c, f \text {, }\end{array}$ & $<20(21.81 \%) ;>20$ (78.19\%) \\
\hline Building material/ barn ${ }^{a, f}$ & $\begin{array}{l}\text { Masonry (97.48 \%); wood and mixed } \\
(2.52 \%)\end{array}$ \\
\hline Type of feeder ${ }^{b, c, f}$ & $\begin{array}{l}\text { Conical semiautomatic }(81.75 \%) \text {; others } \\
(18.25 \%)^{d}\end{array}$ \\
\hline Type of drinker ${ }^{\mathrm{a}, \mathrm{f}}$ & Nipple (98.66 \%); water cup (1.34 \%) \\
\hline Water source ${ }^{\mathrm{b}, \mathrm{f}}$ & $\begin{array}{l}\text { Well / headwater (55.19\%); treated water } \\
(44.81 \%)\end{array}$ \\
\hline Water pipes materiala, ${ }^{a}$ & $\begin{array}{l}\text { Hose }(1.48 \%) \text {; PVC pipe }(97.18 \%) \text {; mixed } \\
(1.34 \%)\end{array}$ \\
\hline Roof material ${ }^{b, f}$ & Clay (87.39 \%); asbestos / zinc (12.61 \%) \\
\hline $\begin{array}{l}\text { Material used to separate } \\
\text { the pens } \mathrm{b}^{\mathrm{f}} \mathrm{f}\end{array}$ & $\begin{array}{l}\text { Wood or masonry }(18.69 \%) \text {; mixed } \\
(81.31 \%)\end{array}$ \\
\hline Floor material ${ }^{\mathrm{a}, \mathrm{f}}$ & Concrete (100 \%) \\
\hline Pens with shallow pools ${ }^{\mathrm{a}, \mathrm{f}}$ & Yes (99.85 \%); no (0.15 \%) \\
\hline Slurry tank $k^{\mathrm{a}, \mathrm{f}}$ & Yes (100\%) \\
\hline Electricity supply ${ }^{\mathrm{a}, \mathrm{f}}$ & Yes (100 \%) \\
\hline Waste lagoons $s^{\mathrm{a}, \mathrm{f}}$ & Yes (100 \%) \\
\hline Ventilation fans $s^{\mathrm{a}, \mathrm{f}}$ & Yes (2.52 \%); no (97.48 \%) \\
\hline Exhaust fans $s^{\mathrm{a}, \mathrm{f}}$ & No (100 \%) \\
\hline Humidifiers / nebulizers ${ }^{\mathrm{b}, \mathrm{g}}$ & Yes (25.71 \%); no (74.29 \%) \\
\hline Composters ${ }^{\mathrm{a}, \mathrm{f}}$ & Yes (98.37\%); no (1.63\%) \\
\hline Trees around the facilities ${ }^{b, f}$ & Yes (43.62 \%); no (56.38 \%) \\
\hline $\begin{array}{l}\text { Barn's position relative to } \\
\text { the sun }{ }^{b, f}\end{array}$ & $\begin{array}{l}\text { Diagonal / contrary ( } 44.07 \%) \text {; parallel } \\
(55.93 \%)\end{array}$ \\
\hline Number of feed used ${ }^{a, f}$ & Five (100 \%) \\
\hline $\begin{array}{l}\text { Different feeds according } \\
\text { to the sex } x^{a, f}\end{array}$ & No (100\%) \\
\hline Feed form ${ }^{a, f}$ & Pelleted (100\%) \\
\hline Shock with antibiotics ${ }^{\mathrm{a}, \mathrm{f}}$ & Yes (100 \%) \\
\hline $\begin{array}{l}\text { Routes used to administer } \\
\text { antibiotics }^{\mathrm{a}, \mathrm{f}}\end{array}$ & Water (1.19\%); water and feed (98.81 \%) \\
\hline Programs used ${ }^{\mathrm{a}, \mathrm{f}}$ & Ractopamine / immunocastration (100 \%) \\
\hline Labour force ${ }^{b, f}$ & Unfamiliar (24.48 \%); familiar (75.52 \%) \\
\hline $\begin{array}{l}\text { Number of employed } \\
\text { genetic } c^{\text {aff }}\end{array}$ & Three (100 \%) \\
\hline Breeds used ${ }^{a, e}$ & Large White / Landrace / Pietrain (100 \%) \\
\hline Sexed batches ${ }^{a, f}$ & No (100\%) \\
\hline Sex segregation in pens $s^{\mathrm{a}, \mathrm{f}}$ & Yes (100 \%) \\
\hline
\end{tabular}

Table 2 Description of independent categorical variables and their percentage of occurrence in the company (Continued)

\begin{tabular}{ll}
\hline $\begin{array}{l}\text { Ileitis, enzootic pneumonia, } \\
\text { meningitis }\end{array}$ & Yes (100\%) \\
$\begin{array}{l}\text { Glasser's disease, } \\
\text { erysipela, }\end{array}$ & No (100\%) \\
Origin $^{\mathrm{a}, \mathrm{c}, \mathrm{e}, \mathrm{i}}$ & SPU (42.9\%); farrow-to-finish units (57.1\%) \\
Sex $^{\mathrm{b}, \mathrm{c}, \mathrm{h}}$ & Barrows (11.85\%); females (12.92\%); mixed \\
& $(75.23 \%)$
\end{tabular}

${ }^{a}$ Variables initially rejected to the statistical analysis due to the absence of

variability among its categories

bariables initially considered to the statistical analysis

'Variables included in the final models

dOthers: composed mostly by linear dump type (17.2 \%) and a few farms with

a linear semiautomatic one (1.1\%)

${ }^{\text {e}}$ Considering 683 batches as experimental units $(n)$

${ }^{\mathrm{f}} n=674$

${ }^{9} n=669$

$\mathrm{h}_{n}=650$

iPercentage of batches composed by animals coming either from a specialized piglet production unit (SPU) or from different farrow-to-finish units

finish farms. The regression analysis indicated that for each kilogram of IW, there was an increase of approximately $0.008 \pm 0.002 \mathrm{~kg}$ in DFI, and for each kilogram of FW, DFI increased by approximately $0.01 \pm 0.0005 \mathrm{~kg}$, as presented in Table 3.

\section{Feed conversion ratio}

The average FCR was $2.45 \pm 0.12$ (range 2.15 to 2.86) (Table 1). Multivariate regression analysis showed that FCR was influenced by the number of pigs per pen $(P<$ 0.001), type of feeder $(P=0.04)$, ORIGSEX $(P<0.001)$, IW $(P<0.001)$, FW $(P<0.001)$ and DGF $(P<0.001)$ (Table 5$)$. The model without predictors (the null model) for FCR had a total variance of 0.015261 , where 0.002331 (15.3\%) was observed between farms whereas 0.01293 (84.7 \%) was between batches from the same farm. The multivariate model reduced the residual variance of FCR to 0.005516 , which indicated that approximately $64 \%$ of its total variance was explained by the predictors in the final model (Table 6). The residual distribution of FCR is shown in Fig. 2. The percentages of variability explained between farms and between batches from the same farm were 33.5 and $69.3 \%$, respectively (Table 6).

Feed conversion ratio improved by $6.0 \pm 1.2$ points when animals were kept at less than 20 per pen compared to batches with more than 20 animals per pen. The type of feeder had also an effect, with nonautomatic feeders (mainly linear dump type) improving FCR by $3.0 \pm 1.4$ points. Regarding ORIGSEX, there was an improvement in FCR of approximately $5.0 \pm 1.0$ points for batches of females from SPU and 3.0 \pm 1.0 points for mixed-sex batches from SPU compared to mixed-sex batches from farrow-to-finish farms. Multivariate regression analysis showed that FCR improved by approximately $3.5 \pm 0.2$ points for each additional 
Table 3 Estimates of the effects of the factors studied on daily feed intake (in kilograms per pig) in 683 batches from 93 grow-finishing pig farms

\begin{tabular}{|c|c|c|c|c|c|c|}
\hline \multirow[t]{2}{*}{ Variable } & \multirow[t]{2}{*}{ Category } & \multirow{2}{*}{$\begin{array}{l}\text { Mean } \\
(\mathrm{kg})\end{array}$} & \multirow[t]{2}{*}{ Estimate (s.e.) } & \multicolumn{3}{|c|}{$\underline{95 \% \mathrm{CL}}$} \\
\hline & & & & Low & Upper & $P$-value \\
\hline Intercept & & - & $0.73(0.07)$ & 0.58 & 0.88 & $<0.001$ \\
\hline \multirow[t]{2}{*}{$N^{\circ}$ pigs per pen } & $<20$ & 2.11 & $-0.04(0.01)$ & -0.06 & -0.02 & $<0.001$ \\
\hline & $>20$ & 2.16 & 0 & - & - & - \\
\hline \multirow[t]{2}{*}{ Type of feeder } & Others (linear dump) & 2.12 & $-0.03(0.01)$ & -0.05 & -0.003 & 0.03 \\
\hline & Conical semiautomatic & 2.15 & 0 & - & - & - \\
\hline \multirow[t]{4}{*}{ ORIGSEX } & SPU / barrows & 2.15 & $0.02(0.01)$ & 0.005 & 0.04 & 0.009 \\
\hline & SPU / females & 2.12 & $-0.01(0.01)$ & -0.03 & 0.003 & 0.12 \\
\hline & SPU / mixed & 2.13 & $0.0004(0.0071)$ & -0.013 & 0.014 & 0.95 \\
\hline & Farrow-to-finish / mixed & 2.13 & 0 & - & - & - \\
\hline IW & & - & $0.008(0.002)$ & 0.004 & 0.013 & $<0.001$ \\
\hline FW & & - & $0.01(0.00)$ & 0.01 & 0.01 & $<0.001$ \\
\hline
\end{tabular}

kilogram of IW and by approximately $1.0 \pm 0.0$ points for each additional kilogram of FW. The DGF also influenced FCR, with each day in the GF phase being approximately $1.5 \pm 0.0$ points worse, as demonstrated in Table 5.

\section{Discussion}

In this study, all the factors included in the final models had an influence on the dependent variables, and the total variance of DFI and FCR accounted by the models was 50 and $64 \%$, respectively. The final models developed by Agostini et al. [14] explained $62 \%$ of the total variance of total feed intake and $24.8 \%$ of FCR whereas the one developed by Oliveira et al. [8] explained $81 \%$ of the total variance of DFI. The difference between the percentages of variance explained in these studies may be due to the difference between the variability of the factors studied.

One aspect observed in this study concerns the variability explained between farms and between batches within a farm with the multivariate models of DFI and FCR. Approximately 43.3 and $69.3 \%$ of the variability of

Table 4 Variance observed between farms and between batches within a farm for model without predictors (null model) and multivariate model (full model) and percentage of variance explained by the variables included in the final model for daily feed intake

\begin{tabular}{|c|c|c|c|c|c|}
\hline \multirow[b]{2}{*}{ Effect } & \multicolumn{2}{|l|}{ Null model } & \multicolumn{2}{|c|}{ Full model } & \multirow{2}{*}{$\begin{array}{l}\text { Variance } \\
\text { explained } \\
\text { (\%) }\end{array}$} \\
\hline & Variance & $\%$ & Variance & $\%$ & \\
\hline Farm & 0.00346 & 36.3 & 0.00136 & 28.2 & 60.8 \\
\hline Batches (Farm) & 0.00608 & 63.7 & 0.00345 & 71.8 & 43.3 \\
\hline Total & 0.00954 & 100.0 & 0.00481 & 100.0 & 49.6 \\
\hline
\end{tabular}

DFI and FCR, respectively, was explained between batches from the same farm. This greater proportion of the variability between batches explained in a farm for FCR is due to the inclusion of the variable DGF (a variable taken per batch, and not per farm) in the model; this variable is not included in the model for DFI.

With respect to the number of pigs per pen, there was a decrease of DFI and improve of FCR in pens that had less than 20 animals throughout the GF phase. The analysis of the social changes due to an increased number of animals in the pen has a great importance for animal welfare and for productivity [16]. According to Schmolke et al. [17], one concern about large group size is the reduced growth rate. Street and Gonyou [18] found that pigs housed in small groups (18 animals) during the GF phase reached $3 \%$ more weight than those housed in large ones (108 animals). FCR was also better (6\%) in small groups, and this was more evident at the end of the study $(14 \%$ more efficient than those housed in large groups). These results were similar to

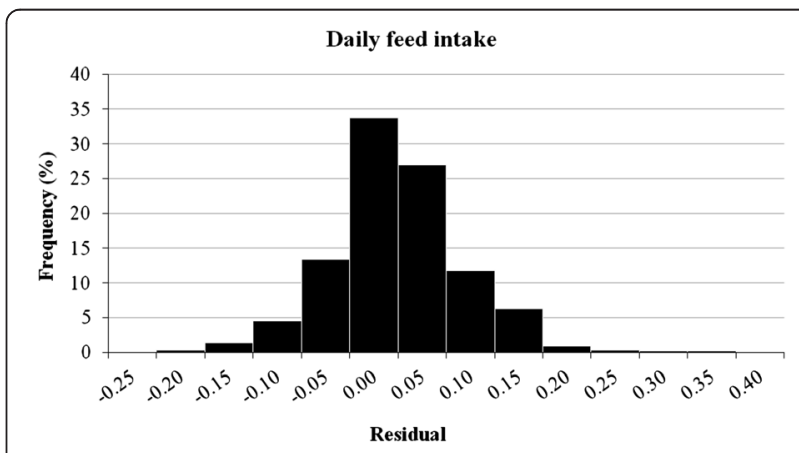

Fig. 1 Residual distribution of the effects of the factors studied on daily feed intake in 683 batches from 93 grow-finishing pig farms 
Table 5 Estimates of the effects of the factors studied on feed conversion ratio in 683 batches from 93 grow-finishing pig farms

\begin{tabular}{|c|c|c|c|c|c|c|}
\hline \multirow[t]{2}{*}{ Variable } & \multirow[t]{2}{*}{ Category } & \multirow[t]{2}{*}{ Mean $(\mathrm{kg} / \mathrm{kg})$} & \multirow[t]{2}{*}{ Estimate (s.e.) } & \multicolumn{3}{|c|}{$95 \% \mathrm{CL}$} \\
\hline & & & & Low & Upper & $P$-value \\
\hline Intercept & & - & $1.43(0.10)$ & 1.23 & 1.62 & $<0.001$ \\
\hline \multirow[t]{2}{*}{$\mathrm{N}^{\circ}$ pigs per pen } & $<20$ & 2.40 & $-0.05(0.01)$ & -0.07 & -0.03 & $<0.001$ \\
\hline & $>20$ & 2.45 & 0 & - & - & - \\
\hline \multirow[t]{2}{*}{ Type of feeder } & Others (linear dump) & 2.41 & $-0.03(0.01)$ & -0.06 & -0.00 & 0.04 \\
\hline & Conical semiautomatic & 2.44 & 0 & - & - & - \\
\hline \multirow[t]{4}{*}{ ORIGSEX } & SPU/barrows & 2.43 & $-0.02(0.01)$ & -0.03 & 0.00 & 0.09 \\
\hline & SPU/females & 2.40 & $-0.05(0.01)$ & -0.07 & -0.03 & $<0.001$ \\
\hline & SPU/mixed & 2.42 & $-0.03(0.01)$ & -0.04 & -0.01 & $<0.001$ \\
\hline & Farrow-to-finish/mixed & 2.44 & 0 & - & - & - \\
\hline IW & & - & $0.035(0.002)$ & 0.03 & 0.04 & $<0.001$ \\
\hline FW & & - & $-0.01(0.00)$ & -0.01 & -0.01 & $<0.001$ \\
\hline DGF & & - & $0.015(0.001)$ & 0.01 & 0.02 & $<0.001$ \\
\hline
\end{tabular}

s.e. standard error, CL confidence level, ORIGSEX variables "origin " and "sex" combined, SPU specialized piglet production unit, IW initial weight, FW final weight, DGF duration of the grow-finishing phase

those found by Vermeer et al. [19], who found that pigs kept in larger groups in the GF phase grew slower. A large group size can provide greater opportunities for exploration and freedom of movement. Thus, during the grower phase, the poorer growth rate may be explained by the fact that part of dietary energy is rather directed to satisfy the demands of greater locomotor activities of animals [20], resulting in worse FCR. Some pig companies may choose to build larger pens (with more animals per pen but no change in space allowance per animal) to better use the space of the barns by reducing the area that would be used to runners and partitions. However, the increase in efficiency offered by the construction of large spaces together with the reduction of work required per pig must be counterposed to the reduction in growth rate during the phases of post-weaning and growth when animals are housed in large groups [20]. Anyway, new studies on the subject should take into account the statements made by Estevez et al. [16], in which the search for the so-called "optimum group" is somewhat guaranteed to fail. Group sizes will vary not

Table 6 Variance observed between farms and between batches within a farm for model without predictors (null model) and multivariate model (full model) and percentage of variance explained by the variables included in the final model for feed conversion ratio

\begin{tabular}{|c|c|c|c|c|c|}
\hline \multirow[b]{2}{*}{ Effect } & \multirow{2}{*}{$\begin{array}{l}\text { Null model } \\
\text { Variance }\end{array}$} & \multirow[b]{2}{*}{$\%$} & \multicolumn{2}{|c|}{ Full model } & \multirow{2}{*}{$\begin{array}{l}\text { Variance } \\
\text { explained } \\
(\%)\end{array}$} \\
\hline & & & Variance & $\%$ & \\
\hline Farm & 0.00233 & 15.3 & 0.00155 & 28.1 & 33.5 \\
\hline Batches (Farm) & 0.01293 & 84.7 & 0.00397 & 71.9 & 69.3 \\
\hline Total & 0.01526 & 100.0 & 0.00552 & 100.0 & 63.9 \\
\hline
\end{tabular}

only according to the animal species but also according to the complexity of environmental factors involved, such as the availability and location of food.

The type of feeder significantly affected DFI and FCR. The use of "other" feeder types (most commonly, the linear dump one) resulted in reduced DFI and better FCR over the use of conical semiautomatic feeder. The cost and the need to modify the facilities make experiments with different types of feeders difficult to conduct [21]. Studies that have related the performance parameters between two type of feeders have included comparisons between those that simultaneously provide feed and water to feed animals with those that offer only dry feed [14, 22, 23], comparisons between feeders with a single space for animals versus those that offer multiple spaces [14, 22-24], and evaluations of the effects of changing the type of feeder between the growing and finishing phases [25]. Changing feeder

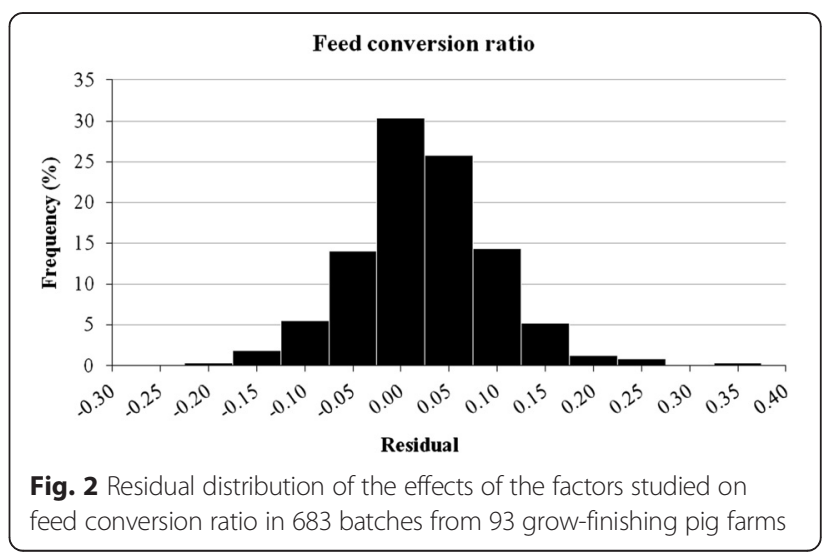


when animals are transferred to GF housing leads to reduced feed intake and performance in the first week after the change, but no negative effect on performance over the entire finishing phase [25]. Comparisons with the results of this study are therefore limited, given the limited information on the subject and because of the wide variation in existing feeders already studied.

The type of feeder may influence feed wastage. In commercial farm conditions, as feed wastage is not subtracted from the actual consumption, the increased wastage results in higher DFI and worse FCR, since the feed is not being utilized for animal growth. Agostini et al. [14] observed a reduction in feed intake without affecting weight gain, when pigs were fed in troughs that provided a unique space associated with a drinker. This could be due to the lower feed wastage with this equipment. In the present study the lower DFI observed in pigs fed in non-conical semiautomatic feeders (mainly linear dump one) might be related to the reduced feed wastage, which leads to an enhanced FCR. In this regard, the regulation of feeders should be considered because when these equipment, such as conical semiautomatic feeders, are inappropriately regulated, feed wastage can increase significantly.

Regarding the variables ORIGSEX, barrows from SPU have a higher DFI than females and mixed-sex batches from SPU as well as mixed-sex batches from farrow-tofinish farms. As for FCR, batches of females and mixedsex batches from SPU showed better performance than batches of barrows originating from SPU and mixedsex batches from farrow-to-finish farms.

The company evaluated in the present study has one specialized piglet production unit (SPU), which produces about 1,600 piglets per week that are housed in GF units. SPU are very common in the Brazilian pig industry. Commonly they adopt all-in all-out management, ensuring better health for the animals sent to GF farms. However, some GF units also receive piglets from farrow-to-finish farms [26], whose investments in animal health are usually smaller. Therefore, it is not uncommon for some of these farms to also be close to other farms without proper biosecurity, which facilitates the transmission of infectious agents. The better health of piglets from SPU may explain their higher DFI and better FCR.

For sex, these results corroborate those of Morales et al. [27] who observed a higher DFI (6.1 \%) for barrows than for females in the GF phase (from 62 to 174 days of age), and Bünzen et al. [28] who observed that males can consume from 10 to $19 \%$ more feed between 60 and $105 \mathrm{~kg}$ than females. Sundrum et al. [29] and Brustolini and Fontes [30] showed that due to the lower feed intake, females require approximately six days extra to reach the slaughter weight of $120 \mathrm{~kg}$.

\section{Conclusions}

In the evaluated conditions, the results showed that GF pigs had a higher DFI and worse FCR when: a) housed in pens with more than 20 animals, b) fed in conical semiautomatic feeder and c) batches were composed by barrows coming from specialized piglet production unit and mixed-sex coming from farrow-to-finish units.

The design of this study gives to pig company and their farms a way to predict the weight of these factors on their performance indices and it seems to be an effective tool to assist technicians and producers in taking management decisions.

\section{Competing interests}

The authors declare that they have no competing interests.

\section{Authors' contributions}

CP drafted the paper. AN, CD, RS, MJ, JN and JA participated in the design and collected the data. PA performed the statistical analysis of data and helped drafting and formatting the paper. JG and CS conceived the original idea and design and participated in the analysis of results and preparation of the manuscript. All authors read and approved the final manuscript.

\section{Acknowledgements}

Firstly, we thank the cooperative participants, who trusted us with the data from their farms so that this study could be developed. We also thank the public research project funded by the Spanish Ministry of Education (AGL 2011-29960), in which this study was developed.

\section{Author details}

'Departamento de Zootecnia, Universidade Estadual de Londrina, 86051-970 Londrina, Brazil. ${ }^{2}$ Grup de Nutrició, Maneig i Benestar Animal, Department de Ciència Animal i dels Aliments, Universitat Autònoma de Barcelona, 08193 Bellaterra, Spain.

Received: 17 October 2015 Accepted: 27 January 2016

Published online: 01 March 2016

\section{References}

1. van Heugten E. Growing-finishing swine nutrient recommendations and feeding management. In: Meisinger DJ, editor. National Swine Nutrition Guide. Ames: North Carolina State University Press; 2010. p. 80-96.

2. Losinger WC. Feed-conversion ratio of finisher pigs in the USA. Prev Vet Med. 1998;36:287-305.

3. Cline TR, Richert BT. Feeding Growing finishing pigs. In: Lewis AJ, Southern LL, editors. Swine Nutrition. 2nd ed. Boca Raton: CRC Press; 2001. p. 717-24.

4. Quiles A, Hervia ML. Factores que influyen en el consumo de piensos en los cerdos. Prod Anim. 2008;248:6-19.

5. Gispert M, Font I, Furnols GM, Velarde A, Diestre A, Carrión D, et al. Relationships between carcass quality parameters and genetic types. Meat Sci. 2007;77:397-404.

6. Niemi JK, Sevón-Aimonen ML, Pietola K, Stalder KJ. The value of precision feeding technologies for grow-finish swine. Livest Prod Sci. 2010;129:13-23.

7. Martinez J, Peris B, Gómez EA, Corpa JM. The relationship between infectious and non infectious herd factors with pneumonia at slaughter and productive parameters in fattening pigs. Vet J. 2009;179:240-6.

8. Oliveira J, Yusa E, Guitián FJ. Effects of management, environmental and temporal factors on mortality and feed consumption in integrated swine fattening farms. Livest Prod Sci. 2009;123:221-9.

9. Agostini PS, Gasa J, Manzanilla EG, Silva CA, Blas C. Descriptive study of production factors affecting performance traits in growing-finishing pigs in Spain. Span J Agric Res. 2013;11:371-81.

10. Agostini PS, Manzanilla EG, Blas C, Fahey AG, Silva CA, Gasa J. Managing variability in decision making in swine growing-finishing units. Ir Vet J. 2015;68:1-13. 
11. Villalba D. Construcción y utilización de un modelo estocástico para la simulación de estrategias de manejo invernal en rebaños de vacas nodrizas. Universitat de Lleida, Lleida: Tesis Doctoral; 2000.

12. Gibon A, Sibbald AR, Thomas C. Improved sustainability in livestock systems, a challenge for animal production science - Introduction. Livest Prod Sci. 1999;61:107-10.

13. Dent JB, Edwards JG, Mcgregor MJ. Simulation of ecological, social and economic factors in agricultural systems. Agric Syst. 1995;49:337-51.

14. Agostini PS, Fahey AG, Manzanilla EG, O'Doherty JV, Blas C, Gasa J. Management factors affecting mortality, feed intake and feed conversion ratio of grow-finishing pigs. Animal. 2014;8:1312-8.

15. Maes D, Duchateau L, Larriestra AJ, Deen J, Morrison RB, de Kruif A. Risk factors for mortality in grow-finishing pigs in Belgium. J Vet Med B Infect Dis Vet Public Health. 2004;51:321-6.

16. Estevez I, Andersen IL, Nævdal E. Group size, density and social dynamics in farm animals. Appl Anim Behav Sci. 2007;103:185-204.

17. Schmolke SA, Li YZ, Gonyou HW. Effect of group size on performance of growing-finishing pigs. J Anim Sci. 2003;81:874-8.

18. Street BR, Gonyou HW. Effects of housing finishing pigs in two group sizes and at two floor space allocations on production, health, behavior, and physiological variables. J Anim Sci. 2008;86:982-91.

19. Vermeer HM, de Greef $\mathrm{KH}$, Houwers HWJ. Space allowance and pen size affect welfare indicators and performance of growing pigs under Comfort Class conditions. Livest Prod Sci. 2014;159:79-86.

20. Turner SP, Allcroft DJ, Edwards SA. Housing pigs in large social groups: a review of implications for performance and other economic traits. Livest Prod Sci. 2003;82:39-51.

21. Heck A. Fatores que influenciam o desenvolvimento dos leitões na recria e terminação. Acta Sci Vet. 2009;37(supl.1):211-8.

22. Gonyou HW, Lou Z. Effects of eating space and availability of water in feeders on productivity and eating behavior of grower/finisher pigs. J Anim Sci. 2000;78:865-70.

23. Patterson DC. A comparison of offering meal and pellets to finishing pigs from self-feed hoppers with and without built-in watering. Anim Feed Sci Tech. 1991;34:29-36.

24. Nielsen $B L$, Lawrence $A B$, Whittemore $C T$. Feeding behavior of growing pigs using single or multi-space feeders. Appl Anim Behav Sci. 1996;47:235-46.

25. Magowan E, McCan MEE, O'Connell NE. The effect of feeder type and change of feeder type on growing and finishing pig performance and behavior. Anim Feed Sci Tech. 2008;142:133-43.

26. Oliveira J, Guitián FJ, Yus E. Effect of introducing piglets from farrow-to-finish breeding farms into all-in all-out fattening batches in Spain on productive parameters and economic profit. Prev Vet Med. 2007;80:243-56.

27. Morales Jl, Cámara L, Berrocoso JD, López JP, Mateos GG, Serrano MP. Influence of sex and castration on growth performance and carcass quality of crossbred pigs from 2 Large White sire lines. J Anim Sci. 2011:89:3481-9.

28. Bünzen S, Apolônio LR, Silva MA. Técnicas de manejo e alimentação para melhoria da conversão alimentar. In: Associação Brasileira dos Criadores de Suínos (ABCS), Produção de Suínos: Teoria e Prática. ABCS. Brasília. 2014; 2014:686-90.

29. Sundrum A, Aragon A, Schulze-Langenhorst C, Bütfering L, Henning M, Stalljohann G. Effects of feeding strategies, genotypes, sex, and birth weight on carcass and meat quality traits under organic pig production conditions. NJAS Wagening J Life Sci. 2011;58:163-72.

30. Brustolini APL, Fontes DO. Fatores que afetam a exigência nutricional de suínos na terminação. In: Associação Brasileira dos Criadores de Suínos (ABCS), Produção de Suínos: Teoria e Prática. Brasília: ABCS; 2014. p. 677-85.

\section{Submit your next manuscript to BioMed Central and we will help you at every step:}

- We accept pre-submission inquiries

- Our selector tool helps you to find the most relevant journal

- We provide round the clock customer support

- Convenient online submission

- Thorough peer review

- Inclusion in PubMed and all major indexing services

- Maximum visibility for your research

Submit your manuscript at www.biomedcentral.com/submit

CBiomed Central 